\title{
Caracterização das lesões parasitárias de ovinos observadas na linha de abate ${ }^{1}$
}

\author{
Welden Panziera², Andréia Vielmo², Cíntia De Lorenzo², Lilian C. Heck², \\ Saulo P. Pavarini ${ }^{2}$, Luciana Sonne ${ }^{2}$, João F. Soares ${ }^{3}$ e David Driemeier ${ }^{2 *}$
}

\begin{abstract}
Panziera W., Vielmo A., De Lorenzo C., Heck L.C., Pavarini S.P., Sonne L., Soares J.F. \& Driemeier D. 2018. [Characterization of parasitic lesions of sheep observed at slaughter line.] Caracterização das lesões parasitárias de ovinos observadas na linha de abate. Pesquisa Veterinária Brasileira 38(8):1491-1504. Setor de Patologia Veterinária, Faculdade de Veterinária, Universidade Federal do Rio Grande do Sul, Av. Bento Gonçalves 9090, prédio 42505, Porto Alegre, RS 91540-000, Brazil. E-mail: davetpat@ufrgs.br

Considering the possibilities of mistaken diagnoses in identifying lesions at meat inspection this study was designed to provide data for a better-educated diagnosis by the meat inspectors through the gross and microscopic characterization of parasitic lesions observed in slaughtered sheep at the inspection line. One hundred and sixty-one samples of parasitic lesions were sampled from various organs of slaughtered sheep during two visits to a sheep abattoir located in the state of Rio Grande do Sul, Brazil. Lesions observed included hydatid cysts, cysticercosis due to Cysticercus ovis and to Cysticercus tenuicollis, sarcocystosis (morphology compatible with Sarcocystis gigantea), fasciolosis (Fasciola hepatica) and oesophagostomosis. Twenty-five point five percent of the 161 samples corresponded to hydatidosis and the hydatid cysts were observed predominantly in the lungs (46.3\%) and liver (41.5\%). On cut surface, the cysts had three different morphological patterns: viable unilocular cysts (34\%); viable multivesicular cysts (31.7\%); and degenerate (unilocular and multivesicular) hydatid cysts (34\%). Cysticercosis by C. ovis (22.4\%) was observed in the myocardium (63.9\%), tongue (13.9\%), masseter (11.1\%), and diaphragm (11.1\%). Morphologically the cysticerci were classified as viable, degenerated or mineralized. Lesions caused by S. Gigantea (19.2\%) were observed in the muscle layer of the esophagus, tongue, and larynx. Grossly there were multiple white nodular structures that contained a fibrous capsule with the lumen filled by translucent and gelatinous material. Cysticercosis by $C$. tenuicollis accounted for $18.6 \%$ of observed parasitic lesions; the cysts adhered to the omentum, mesentery, liver capsule, and serosal surface of gall bladder; grossly the cysts were classified as viable and degenerated. Viable cysts had translucent or slightly opaque walls and contained a single scolex. Degenerated cysts were white, firm and with a thick fibrous capsule and mineralized center. Lesions caused by $F$. hepatica accounted for $7.4 \%$ of the cases and were grossly characterized by variable fibrous thickening of bile ducts which occasionally contained the adult flukes in their lumina. In eight cases there were marked areas of necrosis in the hepatic parenchyma. Lesions caused Oesophagostomum spp. accounted for $6.8 \%$ of the observed parasitic cases and the changes were observed in all cases in the walls of the small and large intestine; in two cases mesenteric lymph nodes were also involved. In the intestines, lesions were characterized by firm well-circumscribed nodules prominent in the serosal surface and also invading the muscle layer. In the lymph nodes marked mineralization obliterated the nodal parenchyma. The correct identification of the various parasitic lesions found in the viscera of sheep in the
\end{abstract}

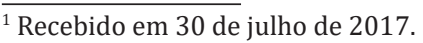

Aceito para publicação em 15 de agosto de 2017.

${ }^{2}$ Setor de Patologia Veterinária, Departamento de Patologia Clínica Veterinária, Faculdade de Veterinária, Universidade Federal do Rio Grande do Sul (UFRGS), Av. Bento Gonçalves 9090, prédio 42505, Porto Alegre, RS 91540-000, Brasil. *Autor para correspondência: davetpat@ufrgs.br
}

\footnotetext{
${ }^{3}$ Laboratório de Protozoologia, Departamento de Patologia Clínica Veterinária, Faculdade de Veterinária, Universidade Federal do Rio Grande do Sul (UFRGS), Av. Bento Gonçalves 9090, prédio 42505, Porto Alegre, RS 91540-000.
} 
abattoir inspection line it is important to dictate the proper destination of affected organs and carcasses. The lesions should be evaluated aiming to determine their infective capacity and to acquire knowledge about their more frequent anatomical sites.

INDEX TERMS: Diseases of sheep, parasitic lesions, abattoir survey, public health, pathology.

RESUMO.- Considerando a possibilidade de erros na identificação das lesões e a necessidade de melhorar o diagnóstico, o objetivo desse trabalho foi caracterizar macroscopicamente e microscopicamente as principais lesões parasitárias observadas em ovinos na linha de abate. Os materiais foram colhidos durante duas visitas a um matadouro frigorífico de ovinos no estado do Rio Grande do Sul. Totalizaram-se 161 amostras com lesões parasitárias de ovinos em diferentes órgãos. As alterações observadas incluíam hidatidose, cisticercose por Cysticercus ovis, cisticercose por Cysticercus tenuicollis, sarcocistose (morfologia compatível com Sarcocystis gigantea), fasciolose (Fasciola hepatica) e esofagostomose. Das 161 amostras, 25,5\% correspondiam a hidatidose, e os cistos hidáticos foram observados, predominantemente, nos pulmões $(46,3 \%)$ e fígado $(41,5 \%)$. Ao corte, os cistos demonstraram três padrões morfológicos: cistos uniloculares viáveis (34\%); cistos multivesiculares viáveis $(31,7 \%)$; e cistos hidáticos (uniloculares e multivesiculares) degenerados (34\%). As lesões de cisticercose por C. ovis $(22,4 \%)$ foram visualizadas no coração $(63,9 \%)$, língua $(13,9 \%)$, músculo masseter $(11,1 \%)$ e diafragma $(11,1 \%)$. Morfologicamente os cisticercos foram classificados em vivos (viáveis), degenerados e mineralizados. Lesões provocadas por S. gigantea $(19,2 \%)$ estavam presentes na túnica muscular do esôfago, na língua e na laringe. Macroscopicamente, observaram-se múltiplas estruturas nodulares brancas que continham uma cápsula fibrosa e lúmen preenchido por material gelatinoso translúcido. Cisticercose por C. tenuicollis representaram 18,6\% das lesões. Os cistos foram observados aderidos no omento, no mesentério, na cápsula do fígado e na vesícula biliar. Morfologicamente os cistos foram classificados como vivos (viáveis) e degenerados. Os cistos vivos apresentavam a parede translúcida ou levemente opaca, contendo um escólex no seu interior. Os cistos degenerados eram brancacentos, firmes, com espessa cápsula fibrosa e centro mineralizado. Lesões provocadas por $F$. hepatica corresponderam a 7,4\% dos casos. As lesões hepáticas caracterizavam-se macroscopicamente por espessamento variável dos ductos biliares por fibrose e ocasionalmente havia exemplares de F. hepatica no lúmen dos ductos. Em oito casos, observaram-se áreas de acentuada necrose do parênquima hepático. Lesões provocadas por Oesophagostomum spp. perfizeram 6,8\% dos casos. As alterações foram observadas no intestino delgado e intestino grosso de todos os ovinos e em dois casos, havia também envolvimento dos linfonodos mesentéricos. Nos intestinos, as lesões caracterizavam-se por nódulos bem delimitados, salientes na serosa, firmes e que invadiam também a camada muscular. Nos linfonodos havia obliteração do parênquima nodal por acentuada mineralização. É extremamente importante a identificação morfológica das diferentes lesões parasitárias encontradas nas linhas de abate em frigoríficos de ovinos, para posterior destino correto das mesmas. As alterações devem ser avaliadas com o intuito principal de reconhecer a sua capacidade infecciosa. Além disso, é fundamental o conhecimento dos locais anatômicos mais comuns em que cada alteração geralmente costuma ocorrer.

TERMOS DE INDEXAÇÃO: Doenças de ovinos, lesões parasitárias, pesquisa em abatedouro, saúde pública, patologia.

\section{INTRODUÇÃO}

A carne ovina vem ganhando espaço no agronegócio brasileiro e aumentando sua participação nesse cenário. Em 2015, o rebanho ovino no Brasil foi estimado em 18, 41 milhões de animais. Nos últimos anos, a criação de caprinos e ovinos vem sendo estimulada por diversos segmentos da cadeia produtiva (IBGE 2013). Além disso, os rebanhos começaram a ser explorados economicamente com a introdução de raças especializadas, melhoramento genético e técnicas de manejo que propiciaram o aumento da produtividade (Viana 2008). O Brasil apresenta destaque como produtor e exportador de proteínas de origem animal para o mundo. 0 comércio mundial de carne de ovinos e caprinos tem pequena participação sobre a produção mundial, pois grande parte do rebanho ainda é destinada ao consumo interno. Entretanto, ao longo dos últimos vinte anos a produção de carne ovina aumentou $21 \%$, sendo que no período de 2000-2010 houve um crescimento de $11,2 \%$, com perspectivas para uma expansão de $32,5 \%$ até 2020 (Souza 2012).

Os bens de consumo resultantes do processo de abate de bovinos e ovinos são carcaças e subprodutos. Os órgãos constituem subprodutos importantes economicamente, pois agregam valor à produção e constituem fontes potenciais de ingredientes alimentares relevantes para a população (Kale et al. 2011). Para garantir a qualidade da carne brasileira e seus subprodutos, é de extrema importância um sistema de inspeção sanitário qualificado, que se estruture em um conjunto de ações a serem desenvolvidas, sistematicamente, no momento oportuno e local adequado, com o propósito básico de garantir a segurança sanitária. Além disso, com a inspeção procura-se minimizar as perdas econômicas da indústria e dos produtores (Tessele et al. 2013). Uma grande dificuldade enfrentada pelos inspetores em estabelecimentos de abate de ovinos tem sido relacionada à falta de segurança em identificar e diagnosticar as diversas enfermidades e, em seguida, estabelecer o destino apropriado para as carcaças e vísceras. Há escassos estudos na literatura relacionados com a caracterização das lesões encontradas em matadouro de ovinos e geralmente os trabalhos abordam as prevalências das doenças que provocaram as condenações. Considerando a possibilidade de erros na identificação das lesões e a necessidade de melhorar o diagnóstico, o objetivo desse trabalho é caracterizar macroscopicamente e microscopicamente as principais lesões parasitárias observadas em ovinos de um matadouro. Assim, o estudo tem o intuito de que a descrição das características morfológicas das lesões possa fomentar a decisão dos inspetores no exame post mortem de ovinos. 


\section{MATERIAL E MÉTODOS}

Amostras de lesões parasitárias de ovinos abatidos foram coletadas aleatoriamente durante duas visitas a um matadouro frigorífico localizado no município de Alegrete, Rio Grande do Sul, Brasil. As coletas foram realizadas nos meses de maio e outubro de 2016. Cada coleta durou aproximadamente duas semanas. 0 frigorífico abate em média 100 ovinos por dia e no somatório dos períodos das coletas foram abatidos 1.479 ovinos de diferentes categorias. 0 estabelecimento é fiscalizado pelo Serviço de Inspeção Municipal (SIM) com adesão ao Sistema Brasileiro de Inspeção de Produtos de Origem Animal (SISBI-POA), que faz parte do Sistema Unificado de Atenção a Sanidade Agropecuária (SUASA). 0 material foi colhido na linha de abate, identificado e fotografado. As lesões foram fixadas em formol a $10 \%$, clivadas, processadas rotineiramente para histologia e coradas pela técnica de hematoxilina e eosina (HE) para avaliação histológica.

\section{RESULTADOS}

Foram analisadas amostras de 161 ovinos com lesões parasitárias presentes em diferentes órgãos. As principais alterações observadas incluíam hidatidose, cisticercose por Cysticercus ovis, sarcocistose (morfologia compatível com Sarcocystis gigantea), cisticercose por Cysticercus tenuicollis, fasciolose (Fasciola hepatica) e esofagostomose (Oesophagostomum spp.). As caracterizações macroscópicas e microscópicas dessas condições serão detalhadas a seguir.

\section{Hidatidose}

Das 161 amostras colhidas, 41 (25,5\%) casos correspondiam a hidatidose. Em relação à distribuição dos cistos, quando havia somente um órgão acometido em cada ovino, os pulmões (46,3\%) foram a localização anatômica mais acometida, seguida do fígado $(41,5 \%)$. Em um ovino $(2,4 \%)$ havia cisto hidático no rim. Quando houve o envolvimento de dois órgãos em um mesmo ovino, fígado e pulmão totalizaram quatro casos $(9,7 \%)$.

Macroscopicamente, os cistos hidáticos caracterizavam-se por estruturas nodulares, transparentes, brancacentas ou amareladas, e que faziam saliência sobre o órgão afetado. As estruturas císticas apresentavam-se distribuídas aleatoriamente pelo parênquima dos órgãos, eram únicas ou múltiplas e variavam de 1 a $6 \mathrm{~cm}$ de diâmetro. Ao corte dos cistos, observaram-se três padrões morfológicos distintos: cistos hidáticos uniloculares viáveis (padrão 1); cistos hidáticos multivesiculares viáveis (padrão 2); e cistos hidáticos (uniloculares e multivesiculares) degenerados (padrão 3). No primeiro padrão, os cistos hidáticos uniloculares viáveis, visualizados em $34 \%$ dos casos (14/41), caracterizavam-se por uma estrutura cística viável envolta por cápsula fibrosa. Eram macios ao corte e apresentavam o lúmen repleto por líquido transparente (líquido hidático). Na porção interna cística havia uma delgada membrana contendo numerosas estruturas brancacentas aderidas, que variavam de 0,1 a $0,3 \mathrm{~cm}$ de diâmetro (cápsulas prolígeras) (Fig.1A). No segundo aspecto morfológico (cistos hidáticos multivesiculares viáveis), observado em $31,7 \%$ dos casos $(13 / 41)$, os cistos também eram macios ao corte e preenchidos por líquido hidático, entretanto, a superfície de corte demonstrava múltiplas estruturas císticas, que por vezes se coalesciam (Fig.1B e 1C). No terceiro padrão de apresentação macroscópica, foram incluídos os cistos hidáticos (uniloculares e multivesiculares) degenerados (14/41, 34\%). Ao corte eles eram firmes e a superfície de corte caracterizava-se pela presença da membrana laminada do parasita colapsada e amarelada, que formava um emaranhado de membranas dentro da cavidade cística (Fig.1D). Em alguns casos as membranas tornaram-se caseosas e mineralizadas.

Os cistos hidáticos uniloculares viáveis (padrão 1) apresentaram microscopicamente uma cápsula espessa externa de tecido conjuntivo fibroso, infiltrada por linfócitos, macrófagos epitelioides, plasmócitos e eosinófilos (porção pertencente ao hospedeiro). Os componentes do cisto que faziam parte do parasito consistiam (a contar da porção mais externa para o interior do cisto) de uma membrana hialina acelular laminada e uma delgada camada germinativa. A partir dessa última, e presas a ela por delicados pedículos, brotavam as cápsulas prolígeras contendo em seu interior vários protoescólices (também chamados de escólices). Os protoescólices apresentavam tegumento, eram acelomados e desprovidos de trato digestivo. Em algumas seções verificaram-se também as ventosas e parte do rostelo com os acúleos (Fig.1E). 0 aspecto histológico dos cistos multivesiculares viáveis (padrão 2) assemelhava-se ao do primeiro padrão. Entretanto, observaram-se múltiplas estruturas císticas ao invés de uma, e cada estrutura continha uma cápsula externa de tecido fibroso (porção do hospedeiro) e os componentes pertencentes ao parasito, idênticos aos descritos previamente. Os cistos hidáticos (uniloculares e multivesiculares) degenerados incluídos no terceiro padrão macroscópico, possuíam histologicamente a membrana laminada degenerada, que por vezes formava um emaranhado dentro da cavidade cística (Fig.1F). 0 epitélio germinativo era hialino e não havia cápsulas prolígeras com protoescólices. Observou-se acentuada reação inflamatória granulomatosa adjacente a cápsula fibrosa ou a membrana laminada, composta por histiócitos dispostos em paliçada, macrófagos epitelioides, células gigantes multinucleadas e mais externamente linfócitos, plasmócitos e eosinófilos. Alguns cistos estavam necrosados e apresentavam marcada mineralização. Nestes casos, a identificação foi realizada pela presença de fragmentos da membrana parasitária laminada em meio à lesão. De maneira geral os cistos hidáticos comprimiam o parênquima pulmonar, hepático e renal adjacente.

\section{Cisticercose (Cysticercus ovis)}

Foram analisados 36 casos $(22,4 \%)$ de cisticercose do total das 161 amostras colhidas. Os locais anatômicos de predileção dos cistos de C. ovis incluíam: coração 63,9\% (23/36), língua 13,9\% (5/36), músculo masseter $11,1 \%$ (4/36) e diafragma 11,1\% (4/36). Morfologicamente os cisticercos foram classificados dentro de três grupos: Grupo 1 - cisticercos vivos (viáveis), Grupo 2 - cisticercos degenerados (mortos), e Grupo 3 - cisticercos mineralizados (mortos). No primeiro grupo, dois cisticercos (5,5\%) foram considerados como vivos (viáveis), e eram caracterizados por lesões císticas com parede translúcida ou levemente opaca, contendo líquido claro e um pequeno nódulo esbranquiçado no interior (escólex) (Fig.2A). Histologicamente (Fig.2B), os cistos eram compostos por uma membrana fracamente eosinofílica, que apresentava numerosas microvilosidades (microtríquias). Da porção interna da membrana invaginava um escólex esférico de Taenia ovis com aproximadamente $1 \mathrm{~mm}$ de diâmetro. 0 escólex apresentava tegumento e foram 

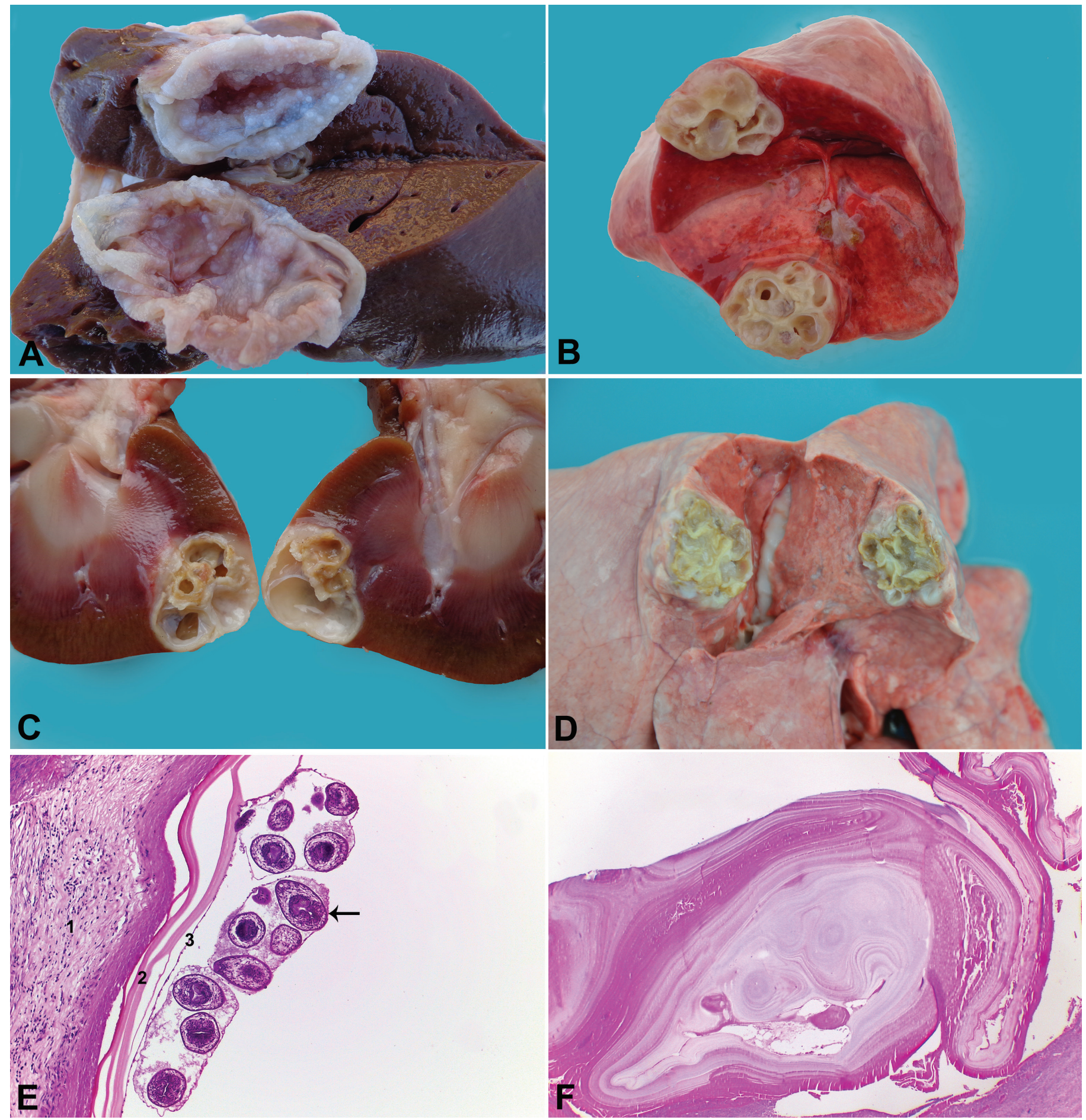

Fig.1. Hidatidose. (A) Superfície de corte de um cisto hidático unilocular no fígado. 0 cisto é único e na sua porção interna há uma delgada membrana contendo numerosas estruturas brancacentas aderidas (cápsulas prolígeras). (B) Superfície de corte de uma hidátide no pulmão demonstrando múltiplas estruturas císticas. Nessa forma de apresentação, o cisto hidático apresenta aspecto multivesicular. (C) Cisto hidático no rim, no qual se evidencia também mais de uma estrutura cística ao corte. (D) Cisto hidático degenerado no pulmão. A membrana laminada do parasita está colapsada e forma um emaranhado de membranas dobradas dentro da cavidade do cisto; o aspecto amarelado indica degeneração. (E) Aspecto microscópico de um cisto hidático viável no pulmão; observa-se uma cápsula espessa externa de tecido conjuntivo fibroso, infiltrada por células mononucleares (porção pertencente ao hospedeiro, 1); o componente do cisto que faz parte do parasito consiste (a contar da porção mais externa para o interior do cisto) de uma membrana hialina acelular laminada (2) e uma delgada camada germinativa (3); a partir dessa última, brotam as cápsulas prolígeras contendo em seu interior vários protoescólices (seta). HE, obj.10x. (F) Histologia de um cisto hidático degenerado no fígado. A membrana laminada está emaranhada e forma várias camadas no lúmen da cavidade cística. HE, obj.10x. 

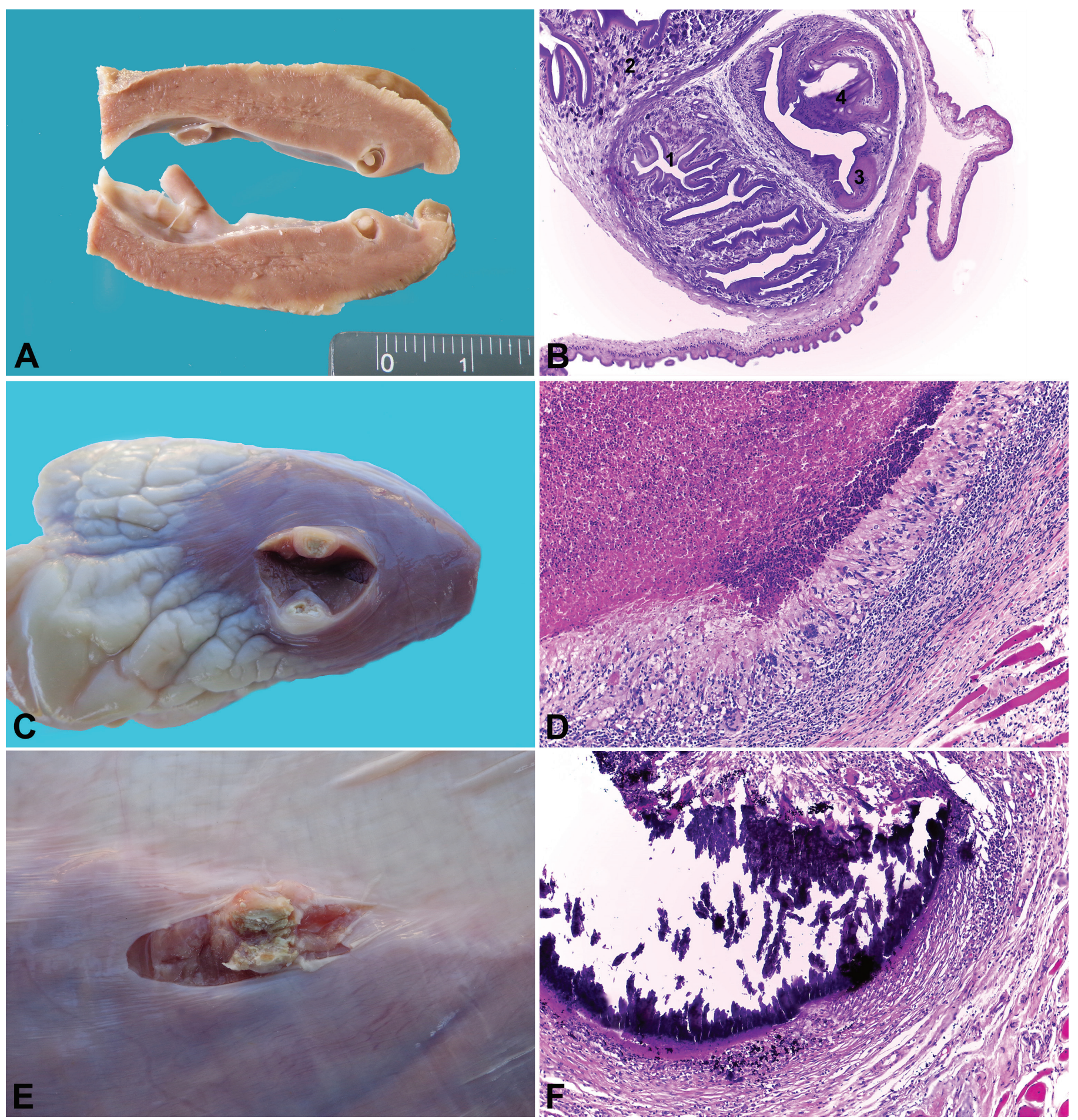

Fig.2. Cisticercose (Cysticercus ovis). (A). Superfície de corte de um cisticerco viável no coração, fixado em formol; o cisto é revestido por uma delgada membrana e no interior há uma estrutura brancacenta e arredondada (escólex). (B). Aspecto histológico do cisto de C. ovis viável observado na imagem anterior; da porção interna da membrana invagina um escólex esférico de Taenia ovis, constituído por tegumento (1), corpúsculos calcários (2), ventosas (3) e parte do rostelo com os acúleos (4). HE, obj.10x. (C) Superfície de corte de um cisticerco degenerado no coração. Observa-se material caseoso branco e friável no centro envolto por cápsula fibrosa. (D) Aspecto histológico do cisticerco degenerado visualizado no coração da Figura 2C; a área central do cisto é composta por necrose caseosa contendo grande quantidade de debris celulares, envolta por acentuado infiltrado inflamatório de histiócitos dispostos em paliçada e células gigantes multinucleadas; mais externamente há infiltrado mononuclear e proliferação de tecido fibrovascular. HE, obj.20x. (E) Cisticerco mineralizado no diafragma com conteúdo cístico amarelado. (F) Histologia do cisticerco mineralizado visualizado no diafragma; a área central cística é composta por acentuada mineralização, circundada por infiltrado inflamatório de histiócitos dispostos em paliçada, ocasionais células gigantes multinucleadas e infiltrado mononuclear; mais externamente observa-se fibrose. HE, obj.20x. 
observadas numerosas e diminutas estruturas basofílicas ovais distribuídas pelo parênquima do parasita (corpúsculos calcários). Em algumas seções verificaram-se estruturas circulares compostas por músculos com fibras em arranjo radial (ventosas) e parte do rostelo com os acúleos. Adjacente à parede do cisto observou-se leve a moderado infiltrado inflamatório de histiócitos dispostos em paliçada, linfócitos, plasmócitos, macrófagos e em menor quantidade eosinófilos.

No segundo grupo (Grupo 2) foram incluídos cisticercos degenerados totalizando 36,1\% (13/36). Macroscopicamente (Fig.2C), observaram-se lesões nodulares que variavam de 1 a $4 \mathrm{~cm}$ de diâmetro, de coloração verde, amarela ou branca. Ao corte dos cistos, observou-se material caseoso verde, amarelo ou branco, envolto por uma cápsula fibrosa. Microscopicamente (Fig.2D), todos os cistos desse grupo caracterizavam-se por formações nodulares compostas por área central de necrose caseosa com focos de mineralização de intensidade variável, rodeados por acentuado infiltrado inflamatório de histiócitos dispostos em paliçada, macrófagos epitelioides, com ocasionais células gigantes multinucleadas e mais externamente linfócitos, plasmócitos, eosinófilos e proliferação de tecido fibrovascular. Em um caso foi possível identificar numerosas estruturas basofílicas ovais (corpúsculos calcários) em meio à área de necrose caseosa.

No terceiro grupo de classificação morfológica dos cisticercos (Grupo 3), foram inseridos os cistos mineralizados (mortos), totalizando 21 cistos ([21/36] 58,3\%). 0 aspecto macroscópico desses cisticercos caracterizava-se por lesões nodulares, amarelas ou brancas, variando de 1-3cm de diâmetro. Ao corte, as estruturas císticas eram firmes e fragmentavam-se, formando pequenas concreções duras e amareladas (Fig.2E). Histologicamente (Fig.2F) observaram-se formações nodulares com área central de acentuada mineralização, rodeadas por moderado a acentuado infiltrado inflamatório de histiócitos dispostos em paliçada, macrófagos epitelioides, com ocasionais células gigantes multinucleadas e mais externamente linfócitos, plasmócitos, eosinófilos e proliferação de tecido fibroso. Um caso demonstrou corpúsculos calcários em meio à mineralização.

\section{Sarcocistose}

Foram observados 31 casos (19,2\%) de sarcocistose. 0 parasito era morfologicamente compatível com $S$. gigantea. As alterações foram visualizadas no esôfago, língua e laringe. Treze ovinos $(41,9 \%)$ apresentaram cistos parasitários somente no esôfago e $18(58,1 \%)$ tinham envolvimento concomitante de esôfago, língua e laringe. Macroscopicamente, observaram-se múltiplas estruturas nodulares salientes no esôfago, língua e laringe, caracterizadas por cistos brancos, redondos a ovais, que variavam de 0,3 a $1 \mathrm{~cm}$ de diâmetro (Fig.3A). Ao corte, as estruturas císticas apresentavam uma cápsula branca e lúmen preenchido por material gelatinoso translúcido (Fig.3B). Na língua, os cistos parasitários eram melhores visualizados quando o órgão era cortado. Microscopicamente, observaram-se numerosas estruturas císticas bem delimitadas em meio a camada muscular dos órgãos afetados (Fig.3C). Os cistos eram delineados por uma cápsula basofílica irregular e uma cápsula adjacente externa de tecido conjuntivo fibroso. Observaram-se numerosos septos ramificados que se originavam da parte interna da cápsula em direção ao lúmen. Os septos sustentavam inúmeras estruturas basofílicas alongadas de $4 \mu \mathrm{m}$ (bradizoítos) (Fig.3D). Não foi evidenciada reação inflamatória adjacente aos cistos.

\section{Cisticercose (Cysticercus tenuicollis)}

Cisticercose por C. tenuicollis representaram 18,6\% (30 casos) das lesões parasitárias do presente estudo. Os cistos foram observados aderidos ao omento, mesentério, cápsula do fígado e vesícula biliar. Morfologicamente os cistos foram classificados como vivos (viáveis) e degenerados (mortos). De maneira geral, eram esféricos ou ovalados e variavam de 3 a $8 \mathrm{~cm}$ de diâmetro. Os cistos vivos de $C$. tenuicollis apresentavam a parede translúcida ou levemente opaca, contendo líquido claro e um pequeno nódulo esbranquiçado no interior (escólex) (Fig.4A). Os cistos classificados como degenerados eram brancacentos, redondos e firmes ao corte. Na superfície de corte, notou-se acentuado espessamento da cápsula cística por fibrose e mineralização. 0 lúmen dessas estruturas císticas era preenchido por material brancacento mineralizado (Fig.4B). Frequentemente havia mais de um cisticerco no mesmo ovino (Fig.4C e 4D). Além disso, cistos vivos e degenerados podiam ser observados concomitantemente (Fig.4E).

Histologicamente, os cistos vivos (viáveis) (Fig.4F) eram compostos por uma membrana que apresentava numerosas microvilosidades (microtríquias). Da porção interna da membrana invaginava um escólex esférico de Taenia hydatigena com aproximadamente $1 \mathrm{~mm}$ de diâmetro. 0 escólex apresentava tegumento e foram observadas numerosas e diminutas estruturas basofílicas ovais distribuídas pelo parênquima do parasita (corpúsculos calcários). Em algumas seções verificaram-se estruturas circulares compostas por músculos com fibras em arranjo radial (ventosas) e parte do rostelo com os acúleos. Adjacente à parede do cisto observou-se leve a moderado infiltrado inflamatório de histiócitos dispostos em paliçada, linfócitos, plasmócitos, macrófagos e em menor quantidade eosinófilos. Os cistos degenerados eram compostos por espessa cápsula de tecido conjuntivo fibroso, com mineralização de intensidade variável e infiltrado inflamatório granulomatoso constituído de macrófagos epitelioides, células gigantes multinucleadas, linfócitos, plasmócitos e escassos eosinófilos. A grande maioria dos cistos degenerados apresentava área central de necrose caseosa com focos de mineralização, rodeados por acentuado infiltrado inflamatório de histiócitos dispostos em paliçada, macrófagos epitelioides, com ocasionais células gigantes multinucleadas e mais externamente linfócitos, plasmócitos e eosinófilos. No centro de alguns cistos observaram-se ainda a membrana parasitária degenerada sem o escólex.

\section{Fasciolose}

Lesões provocadas por Fasciola hepatica corresponderam a 7,4\% (12 casos). Em todos os casos, as lesões foram restritas ao fígado e caracterizavam-se macroscopicamente por variável espessamento dos ductos biliares por fibrose, e em seis ovinos, havia numerosos exemplares de $F$. hepatica no lúmen dos ductos (Fig.5A). Outro achado macroscópico importante, visualizado em oito casos, consistia de áreas multifocais ou focalmente extensas de acentuada necrose do parênquima hepático. Essas áreas eram esverdeadas e amareladas, e ocasionalmente recobertas com fibrina (Fig.5B). Ao corte observavam-se também focos de fibrose, espessamento de ductos biliares e áreas vermelhas enegrecidas (Fig.5C). 

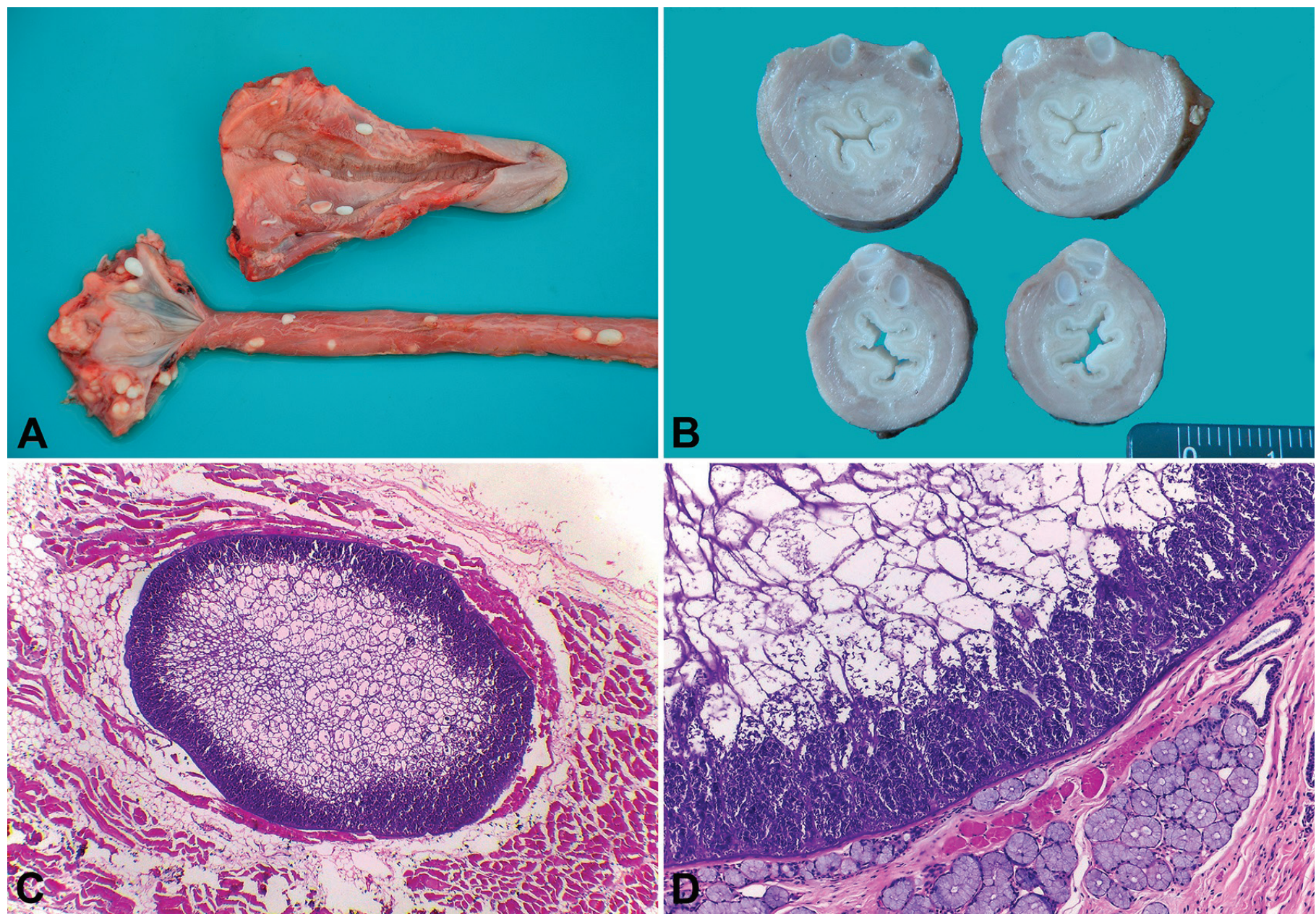

Fig.3. Sarcocistose (Sarcocystis gigantea). (A) Observam-se múltiplas estruturas brancas e nodulares no esôfago e na língua. (B) Corte transversal de um esôfago fixado em formol contendo exemplares de S. gigantea; os parasitos apresentam uma cápsula fibrosa e lúmen preenchido por material gelatinoso translúcido. (C) Aspecto histológico de um cisto de S. gigantea; observa-se uma grande estrutura cística em meio à camada muscular do esôfago. HE, obj.4x. (D) Imagem mais aproximada demonstrando que o cisto é delineado por uma cápsula basofílica irregular e uma cápsula adjacente externa de tecido conjuntivo fibroso; há numerosos septos ramificados que se originam da parte interna da cápsula em direção ao lúmen, e sustentam inúmeros bradizoítos. HE, obj.20x.

Microscopicamente, em todos os casos observou-se leve a acentuado espessamento dos ductos biliares por fibrose e marcada hiperplasia do epitélio ductal. No lúmen de alguns ductos biliares do fígado de seis ovinos, havia cortes transversais de exemplares adultos de trematódeos, morfologicamente compatíveis com $F$. hepatica. Os parasitos eram revestidos por um tegumento eosinofílico externo contendo espinhos e interior preenchido por trato digestivo e trato reprodutor feminino e masculino (hermafrodita). 0 trato digestivo era composto por intestino grosso (ceco) pareado, com pigmento marrom no lúmen. No sistema reprodutor feminino observou-se útero e vitelária (também chamada glândulas vitelogênicas). 0 útero continha em seu interior inúmeros ovos em maturação, revestidos por uma cápsula levemente amarelada. A vitelária era constituída por estruturas glandulares em formato de cachos, sustentadas por uma membrana basal. A porção masculina incluía o testículo com numerosos espermatozoides com formato fusiforme no seu interior (Fig.5D e 5E.).

Em meio ao epitélio hiperplásico dos ductos biliares, nos espaços portas e no parênquima hepático, observou-se moderado a acentuado infiltrado inflamatório de eosinófilos, plasmócitos, linfócitos e macrófagos, alguns com o citoplasma repleto de hemossiderina. Havia também fibrose portal. As áreas necrosadas, visualizadas macroscopicamente em oito ovinos, consistiam de múltiplos focos de acentuada necrose caseosa contendo grande quantidade de debris celulares, circundadas por marcado infiltrado inflamatório de histiócitos dispostos em paliçada, células gigantes multinucleadas, eosinófilos, plasmócitos e linfócitos, além de proliferação de tecido fibrovascular (Fig.5F). Havia ainda, áreas de necrose de coagulação de hepatócitos e hemorragia. Dos oito ovinos com necrose no parênquima, dois apresentaram exemplares de $F$. hepatica no lúmen de alguns ductos biliares que também estavam espessados por fibrose e com hiperplasia do epitélio ductal.

\section{Esofagostomose}

As alterações provocadas por Oesophagostomum spp. perfizeram 6,8\% (11 casos). As lesões foram observadas no intestino delgado (jejuno e íleo) e nos três segmentos do 

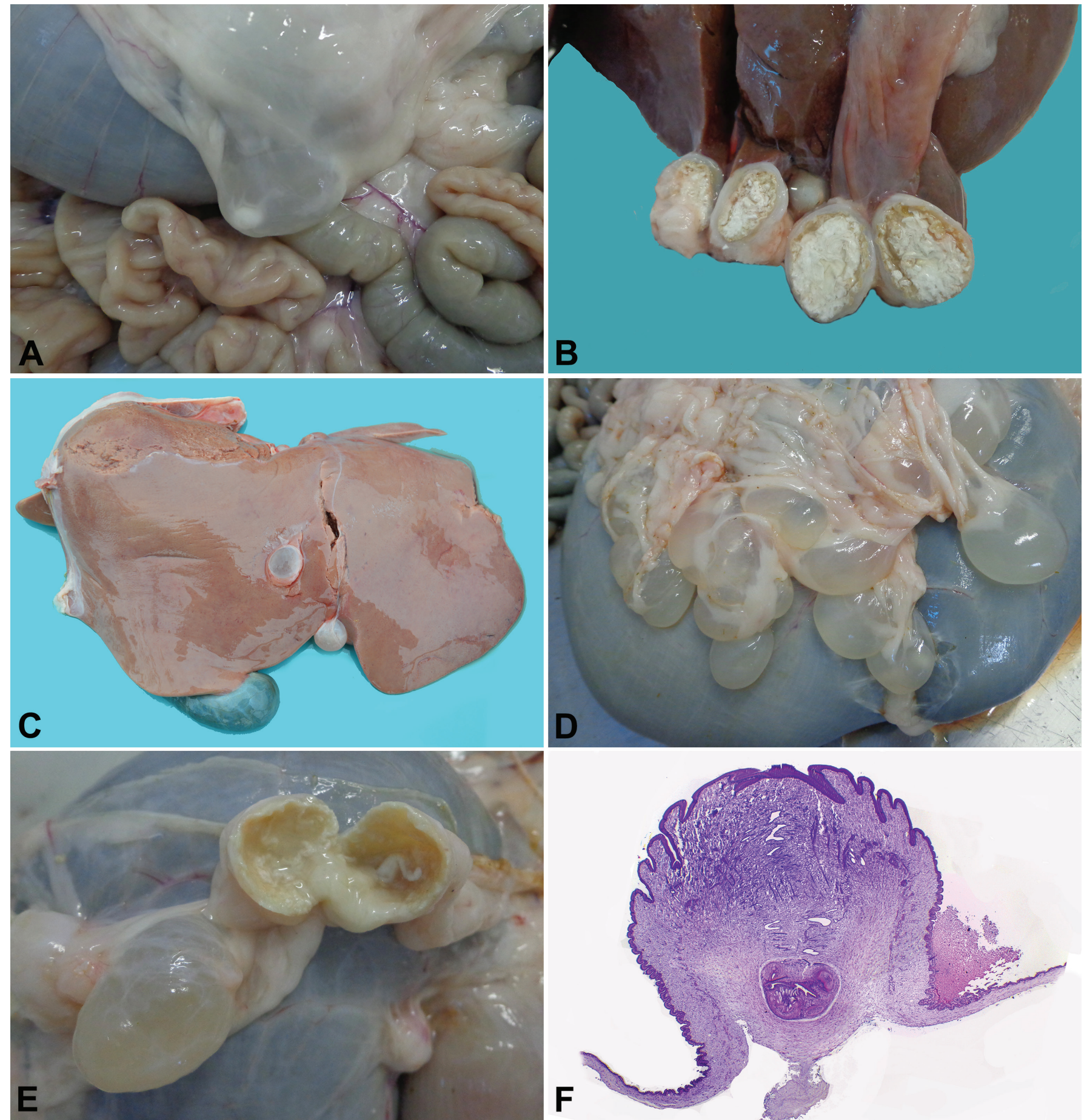

Fig.4. Cisticercose (Cysticercus tenuicollis). (A) Cisto vivo (viável) de C. tenuicollis no omento; o cisticerco possui uma membrana translúcida e é preenchido por líquido claro; no interior do cisto há ainda uma pequena estrutura brancacenta (escólex). (B) Superfície de corte de dois C. tenuicollis degenerados aderidos na cápsula hepática e na vesícula biliar; há acentuado espessamento da parede cística por fibrose e o lúmen está preenchido por material brancacento. (C) Fígado com dois cistos de $C$. tenuicollis viáveis aderidos na cápsula. (D) Múltiplos cisticercos vivos no omento de um mesmo ovino. (E) Cisto vivo e degenerado observado concomitantemente no omento de um ovino; o cisto vivo (não cortado) possui a parede translúcida e líquido claro no seu interior, enquanto que o cisto degenerado (cortado) tem coloração branca e parede espessa. (F) Aspecto histológico de um cisto de C. tenuicollis íntegro; observa-se um escólex esférico de Taenia hydatigena invaginando a partir da membrana. HE, obj.4x.

intestino grosso (ceco, cólon e reto) de todos os ovinos. Em dois casos além do intestino, havia envolvimento dos linfonodos mesentéricos. Nos intestinos, as lesões caracterizavam-se por formações nodulares, bem delimitadas, salientes na serosa e que invadiam também a camada muscular (Fig.6A). Os nódulos parasitários tinham entre 0,3 a $1 \mathrm{~cm}$ de diâmetro, 
geralmente eram firmes ao corte e apresentavam superfície de corte que variava de brancacenta, a esverdeada, amarelada ou amarronzada (Fig.6B). Os linfonodos mesentéricos acometidos apresentavam-se moderadamente aumentados de tamanho, firmes ao corte e na superfície de corte havia obliteração do parênquima nodal pela presença de diminutos nódulos
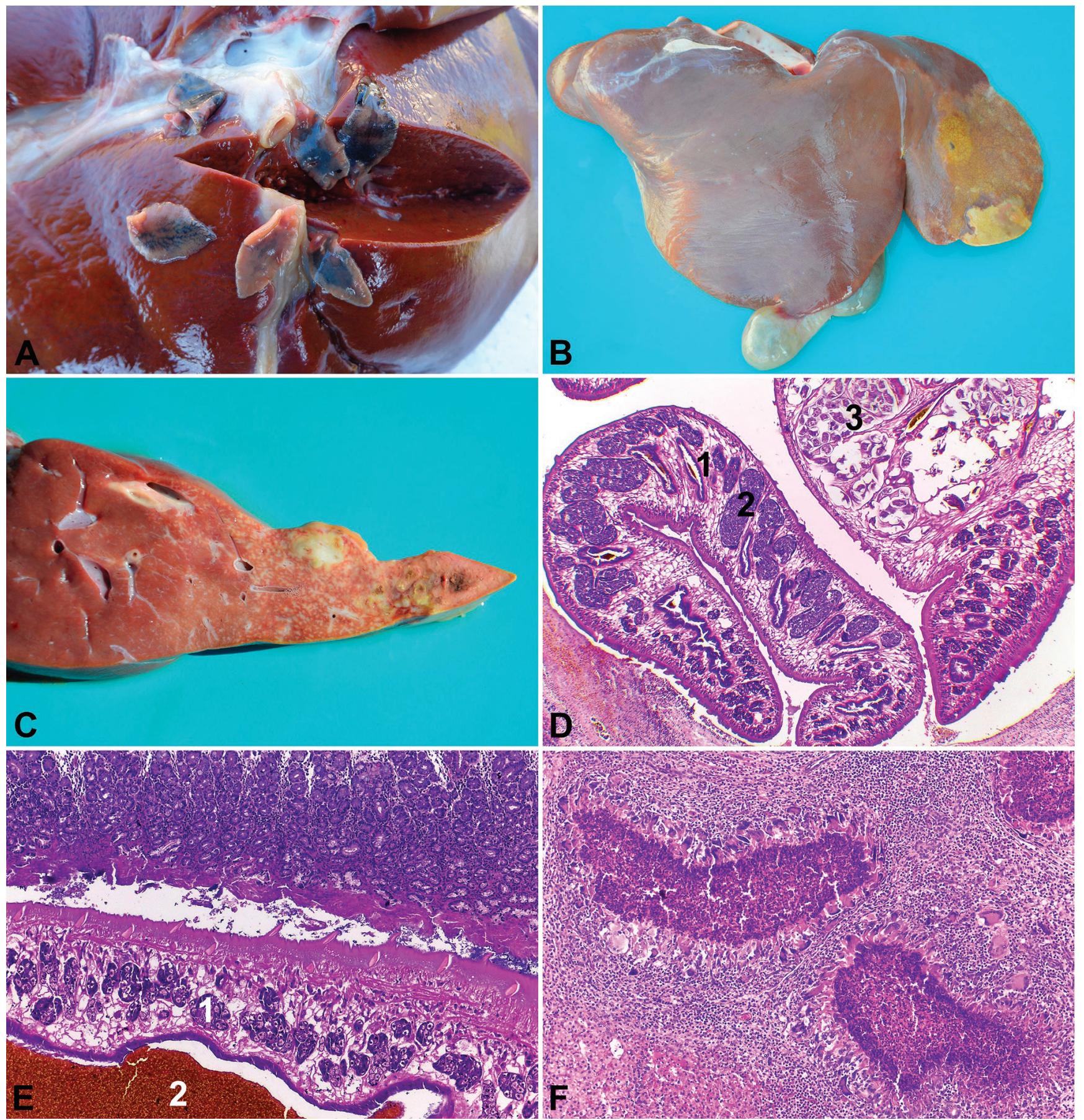

Fig.5. Fasciolose (Fasciola hepatica). (A) Observa-se moderado espessamento de um ducto biliar e numerosos exemplares de $F$. hepatica.

(B) Área focalmente extensa de acentuada necrose no lobo hepático esquerdo. (C) Superfície de corte da área de necrose hepática da Figura 5B; observa-se espessamento de ductos biliares e áreas amareladas e vermelhas enegrecidas. (D) Cortes transversais de dois exemplares adultos de $F$. hepatica no lúmen de um ducto biliar. Nesta imagem, observam-se o trato digestivo composto por intestino grosso (ceco, 1), os testículos com numerosos espermatozoides no seu interior (2) e o útero (3) com inúmeros ovos em maturação. HE, obj.4x. (E) Imagem mais aproximada de F. hepatica dentro de um ducto biliar; o parasito possui um tegumento eosinofílico externo com numerosos espinhos; observa-se também a vitelária (1) constituída por estruturas glandulares em formato de cachos e o ceco (2) preenchido com pigmento marrom no lúmen. Acima, há acentuada hiperplasia do epitélio ductal. HE, obj.20x. (F) Áreas de acentuada necrose caseosa contendo grande quantidade de debris celulares, circundadas por marcado infiltrado inflamatório de células gigantes multinucleadas; mais externamente há infiltrado mononuclear e eosinofílico. HE, obj.20x. 
amarelados a amarronzados, firmes e que se fragmentavam. Havia também áreas esverdeadas de necrose caseosa (Fig.6C).

Microscopicamente, observaram-se numerosos nódulos, bem delimitados, que expandiam a serosa, camada muscular e submucosa do intestino grosso, por vezes deslocando a mucosa (Fig.6D). As estruturas nodulares eram formadas por área central de acentuada necrose caseosa, contendo grande quantidade de debris celulares e focos de intensidade variáveis de mineralização. As áreas necróticas eram circundadas por abundante infiltrado inflamatório de eosinófilos, macrófagos epitelioides, linfócitos, plasmócitos e ocasionais células gigantes multinucleadas, além de leve a moderada fibrose. Em dois casos, nas áreas de necrose, havia cortes transversais de estruturas parasitárias compatíveis morfologicamente com
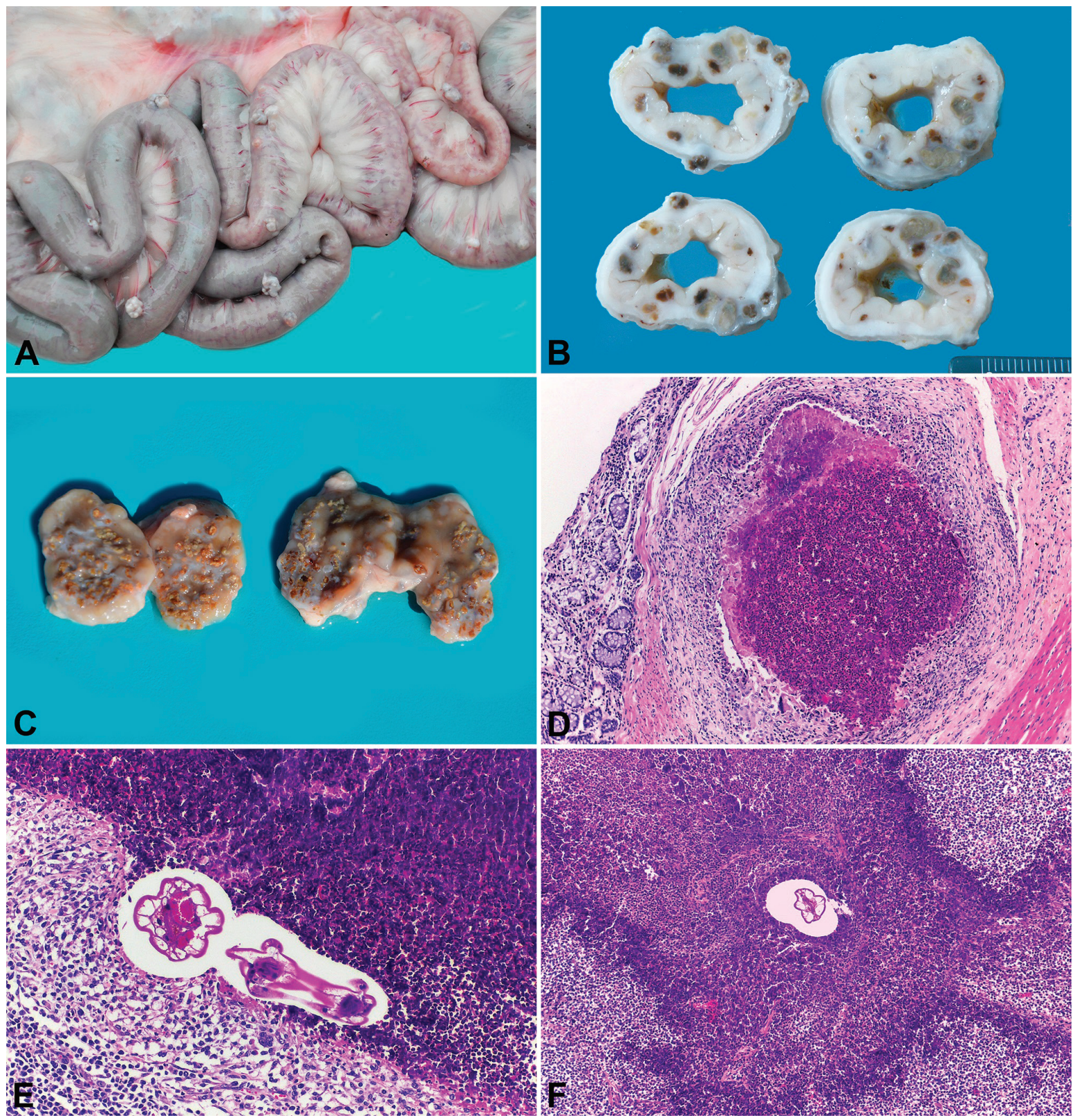

Fig.6. Esofagostomose (Oesophagostomum spp.). (A) Intestino delgado; observam-se numerosos nódulos multifocais salientes na serosa.

(B) Superfície de corte do ceco, demonstrando múltiplas formações nodulares presentes na serosa, camada muscular e submucosa. (C) Superfície de corte de dois linfonodos mesentéricos; observe que o parênquima nodal está obliterado pela presença de diminutos nódulos amarelados a amarronzados. (D) Intestino grosso. Observa-se um granuloma parasitário expandindo a submucosa e deslocando a mucosa, com centro formado por debris celulares, circundado por abundante infiltrado inflamatório granulomatoso e fibrose. HE, obj.10x. (E) Imagem mais aproximada de um granuloma contendo cortes transversais de larvas de Oesophagostomum spp. em meio aos debris celulares; as larvas são compostas por uma cutícula eosinofílica ondulada, musculatura platimiariana, cordas laterais vacuolizadas e intestino; perifericamente a área de necrose, há histiócitos dispostos em paliçada, infiltrado inflamatório mononuclear e ocasionais células gigantes multinucleadas. HE, obj.20x. (F) Área focalmente extensa de necrose caseosa no parênquima de um linfonodo mesentérico contendo corte transversal de uma larva de Oesophagostomum spp. HE, obj.10x. 
larvas de Oesophagostomum spp. As larvas eram compostas por uma cutícula eosinofílica ondulada, musculatura platimiariana, cordas laterais vacuolizadas e trato digestivo (intestino) (Fig.6E). Multifocalmente observou-se ainda material marrom enegrecido homogêneo adjacente às áreas de necrose. As lesões histológicas visualizadas nos linfonodos mesentéricos nos dois ovinos eram semelhantes às descritas no intestino grosso. Em um caso havia cortes transversais de larvas de Oesophagostomum spp. em meio as áreas de necrose caseosa (Fig.6F). Notou-se também acentuada mineralização do parênquima de um linfonodo.

\section{DISCUSSÃO}

Lesões parasitárias constituem as principais causas de condenações de carcaças e órgãos de ovinos em matadouros. Estudos em diferentes partes do mundo demonstram que essas condenações são decorrentes, principalmente, de lesões associadas com hidatidose, cisticercose (Cysticercus ovis e C. tenuicollis) e fasciolose (Scala et al. 2004, Santos et al. 2010, Cardona \& Carmena 2013, Khanjari et al. 2015, Morais et al. 2017). Aspectos semelhantes foram observados nesse estudo, no qual essas doenças também constituíram as principais causas de condenações. Geralmente as infecções parasitárias em ovinos estão diretamente relacionadas aos sistemas produtivos (manejo) de cada propriedade, hábitos, fatores ambientais, fatores climáticos e fatores individuais frente a essas infecções (Giudici et al. 2013).

A hidatidose representa uma importante doença parasitária de caráter zoonótico no mundo e responsável por grandes perdas econômicas para indústria frigorífica e produtores. Vários estudos têm demonstrado que a enfermidade constitui uma preocupação crescente para a saúde pública, pois ela é considerada uma enfermidade emergente ou reemergente em diferentes regiões do mundo (Moro \& Schantz 2009). No ciclo biológico da hidatidose, cisto hidático ou hidátide constitui o estágio larval do cestódeo Echinococcus granulosus, no qual os ovinos, bovinos e humanos são os hospedeiros intermediários e o cão ou canídeos silvestres, os hospedeiros definitivos (Urquhart et al. 1996, Taylor et al. 2010, Bowman 2014). 0 desenvolvimento do cisto hidático no hospedeiro intermediário é lento e a maturidade é alcançada em 6-12 meses (Tessele et al. 2013). Em relação à localização dos cistos hidáticos nesse estudo, o pulmão e o fígado representaram quase a totalidade de órgãos acometidos. Esses constituem os sítios mais comuns de desenvolvimento dos metacestoides em ovinos e bovinos. Na espécie ovina, cerca de $70 \%$ dos cistos ocorrem no pulmão, e 25\% no fígado, e o restante é distribuído em outros órgãos. Em bovinos, 90\% dos cistos hidáticos são observados no fígado, e o restante nos demais órgãos, principalmente pulmão (Barros 2016). Entretanto, diferentemente do observado na literatura para ovinos, a incidência de hidatidose pulmonar $(46,3 \%)$ e hepática $(41,5 \%)$ nesse estudo, foram semelhantes. Geralmente, a oncosfera liberada dos ovos no intestino do hospedeiro intermediário segue pela circulação sanguínea até o fígado, ou pela circulação linfática até o pulmão. No entanto, ocasionalmente as oncosferas escapam para a circulação sistêmica e se desenvolvem em outros órgãos pouco frequentes como baço, rim, coração, osso e encéfalo (Barros 2016). Essa seria uma rota plausível e justificaria a localização incomum do cisto hidático no rim de um ovino nesse estudo.
Macroscopicamente os cistos demonstraram três padrões distintos quando seccionados. 0 segundo padrão morfológico, visualizado em aproximadamente $30 \%$ dos casos de hidatidose, apresentou múltiplas estruturas císticas na superfície de corte. Sugere-se que essa apresentação seja mais frequente em ovinos, já que em bovinos, por exemplo, a maioria dos cistos possui apenas uma cavidade cística e o aspecto multivesicular é raro (Kul \& Yildiz 2010, Tessele et al. 2013). Cistos multivesiculares podem ser formados por queda da pressão intracística ou processos de obstrução, rupturas ou alterações bioquímicas no seu conteúdo, como entrada de bile. Esses processos podem transformar o cisto hidático primitivo (unilocular) em uma hidátide multivesicular (Rey 2013). Os principais diagnósticos diferenciais dos cistos multivesiculares incluem neoplasias e processos inflamatórios, como granulomas e abscessos (Kul \& Yildiz 2010). Outro importante diferencial, entretanto, restrito para a América do Norte, Europa e Ásia, são os cistos hidáticos alveolares, que constituem o estágio larval da tênia Echinococcosis multilocularis. Nesses casos há raro acometimento de bovinos, equinos, suínos e humanos, e essas espécies representam hospedeiros intermediários incomuns. Uma característica morfológica dos cistos alveolares é o brotamento exógeno e a ausência da cápsula de tecido conjuntivo fibroso (Kul \& Yildiz 2010, Bowman 2014). No terceiro padrão de hidatidose, no qual os cistos uniloculares e multivesiculares estavam degenerados, a presença da membrana constituiu a única característica histológica diagnóstica disponível. Esse aspecto também é descrito na literatura (Eberhard 2014). Os cistos mineralizados, por vezes, podem ser confundidos com tuberculose (Higino et al. 2013) ou cistos degenerados de $C$. tenuicullis. As lesões parasitárias são diferenciadas da tuberculose, principalmente, pelo infiltrado inflamatório de histiócitos dispostos em paliçada que circundam a área necrótica ou mineralizada e o infiltrado de eosinófilos. Entretanto, as alterações parasitárias quando degeneradas, podem ser de difícil diferenciação macroscópica entre si e nesses casos, deve-se recorrer à histopatologia. Nas lesões podem estar presentes alguns constituintes do parasito que auxiliam nessa diferenciação.

Cisticercose por $C$. ovis representou outra importante enfermidade nesse estudo, responsável por relevantes condenações. No ciclo biológico dessa doença, C. ovis constitui o estágio larval de Taenia ovis e os cães ou canídeos selvagens são os hospedeiros definitivos e os ovinos ou caprinos os hospedeiros intermediários (Urquhart et al. 1996, Taylor et al. 2010). Músculo cardíaco e músculo esquelético constituíram os locais anatômicos de predileção dos cistos de C. ovis no presente estudo. Dados semelhantes também são descritos na literatura para ovinos (Oryan et al. 1994, Sissay et al. 2008, Erickson 2011, Cooper \& Valentine 2016). Essa predileção pode estar relacionada pelo fato desses locais serem mais irrigados, o que favoreceria a chegada das oncosferas (Taylor et al. 2010). Morfologicamente, embora os cisticercos mineralizados (mortos) demonstrassem maior frequência nesse estudo, é de extrema importância o reconhecimento dos cistos vivos e dos cistos que estão na fase intermediária, ou seja, entre vivos e mineralizados. Sugere-se que na rotina de inspeção, os cisticercos sejam cortados transversalmente para avaliar o aspecto macroscópico da superfície de corte do cisto, pois muitas lesões císticas podem apresentar características de viabilidade infecciosa de $C$. ovis. 
Os ovinos são hospedeiros intermediários de quatro espécies de Sarcocystis: S. gigantea (sinônimo Sarcocystis ovifelis) e Sarcocystis medusiformis, os quais são transmitidos por felinos (hospedeiros definitivos) e constituem espécies menos patogênicas; e Sarcocystis tenella (sinônimo Sarcocystis ovicanis) e Sarcocystis arieticanis, transmitidos por caninos (hospedeiros definitivos), no qual são mais patogênicas e responsáveis por doenças neurológicas e abortos. Os ovinos se infectam com $S$. gigantea quando ingerem oocistos ou esporocistos que são eliminados nas fezes dos gatos (Dubey et al. 1988, Urquhart et al. 1996, Taylor et al. 2010). À semelhança do que é descrito na literatura (Dubey et al. 1988, Dehaghi et al. 2013, Damboriarena et al. 2016, Uzal et al. 2016), os cistos foram observados no esôfago, língua e laringe. A diferenciação entre S. gigantea e as demais espécies de Sarcocystis foi baseado na morfologia dos cistos. S. gigantea e $S$. medusiformis formam cistos macroscópicos, enquanto que $S$. tenella e $S$. arieticanis são caracterizados por cistos microscópicos (Dubey et al. 1988, Dehaghi et al. 2013). Histologicamente, a forma e a espessura da parede podem permitir o diagnóstico definitivo das espécies de Sarcocystis (Dubey et al. 1988). 0 principal diagnóstico diferencial de $S$. gigantea, inclui a espécie $S$. medusiformis. Similar aos casos já descritos, os cistos de S. gigantea observados nesse estudo eram delineados por uma fina cápsula basofílica que apresentava numerosos septos ramificados em direção ao lúmen. $S$. medusiformis também apresenta parede fibrosa, entretanto induz formações de cistos menores, além de possuir distribuição geográfica restrita na Austrália, Nova Zelândia e Irã (Farhang-Pajuh et al. 2014). S. gigantea e $S$. medusiformis são reportados como espécies não-patogênicas, mas estão relacionadas a perdas na indústria frigorífica por condenações e miosites quando ocorre ruptura dos cistos (Damboriarena et al. 2016). Lesões inflamatórias secundárias as rupturas císticas não foram observadas nesse estudo. Diferentemente das espécies previamente mencionadas, $S$. tenella e $S$. arieticanis são patogênicas e formam cistos microscópicos. As estruturas císticas de ambas possuem projeções vilosas e a espécie $S$. arieticanis não apresenta cápsula fibrosa (Dubey et al. 1988).

Diversos estudos demonstram uma alta frequência de cisticercose por $C$. tenuicollis em frigoríficos de ovinos e caprinos (Soares et al. 2012, Singh et al. 2015, Khanjari et al. 2015, Morais et al. 2017). C. tenuicollis constitui o estágio larval de Taenia hydatigena, que possui como hospedeiros intermediários ovinos, caprinos, bovinos e suínos, e como hospedeiros definitivos cães e canídeos selvagens (Urquhart et al. 1996, Taylor et al. 2010). A infecção é prevalente em ovinos, mas em geral é detectada apenas na inspeção. As oncosferas infectantes para os ovinos são transportadas pelo sangue ao fígado, onde migram por aproximadamente quatro semanas, antes de emergir na superfície desse órgão e fixar-se ao peritônio. Posteriormente, de cada oncosfera se desenvolve C. tenuicollis (Urquhart et al. 1996). Nesse estudo, os cistos foram observados aderidos ao omento, mesentério, cápsula do fígado e na vesícula biliar. Geralmente esses constituem os locais de predileção dos cistos de C. tenuicollis (Singh et al. 2015, Barros 2016).

Morfologicamente os cistos neste trabalho foram classificados como vivos (viáveis) ou degenerados (mortos), e frequentemente mais de uma estrutura parasitária no mesmo ovino estava presente. Geralmente não há problemas na identificação dos cistos de $C$. tenuicollis viáveis, pois são estruturas císticas translúcidas com um escólex em seu interior. Entretanto, pode haver dificuldade quando estes cistos estão degenerados e presentes, principalmente, no fígado. Nesses casos, lesões degeneradas de hidatidose tornam-se um importante diagnóstico diferencial. Como discutido previamente, sugere-se que as lesões sejam sempre cortadas transversalmente para avaliar o aspecto macroscópico da superfície de corte. Entretanto, quando as lesões estiverem totalmente mineralizadas essa avaliação torna-se difícil. Nesses casos, um aspecto importante que auxilia macroscopicamente na diferenciação é o fato de que as lesões de $C$. tenuicollis geralmente estão mais superficiais e aderidas na cápsula hepática com pouca invasão do parênquima. Por outro lado, nos casos de hidatidose, as alterações são mais profundas e ocorre maior invasão do parênquima. Raramente, grandes números de cisticercos em desenvolvimento migram ao mesmo tempo no fígado de ovinos, produzindo uma lesão denominada de hepatite cisticercosa, condição cuja lesão macroscópica lembra fasciolose aguda sendo frequentemente fatal (Urquhart et al. 1996, Barros 2016, Cullen \& Stalker 2016). Nenhum caso semelhante a essa condição foi observado neste estudo.

Alterações provocadas por Fascviola hepatica representam outro importante achado na linha de abate de ovinos. Esse parasito, da classe Trematoda, possui como hospedeiros definitivos, principalmente, ovinos e bovinos e como hospedeiros intermediários, caramujos do gênero Lymnaea (Taylor et al. 2010, Bowman 2014). A patogênese da doença está relacionada com o efeito da migração das metacercárias pelo fígado (dano ao parênquima hepático) e a ação dos trematódeos adultos nos ductos biliares. Dependendo do número de metacercárias ingeridas pelo animal, a fasciolose pode ser aguda, subaguda ou crônica. As formas aguda e subaguda são observadas quase exclusivamente em ovinos e raramente em bovinos (Adrien et al. 2013), enquanto que a apresentação crônica é comum em ambas as espécies (Mitchell 2002, Barros 2016, Cullen \& Stalker 2016). As lesões de caráter agudo e subagudo em ovinos podem estar relacionadas a questões evolutivas da espécie e estão diretamente ligadas ao tipo de manejo. Geralmente os ovinos são criados em áreas não alagadas, pois esses locais podem provocar enfermidades nos cascos (footrot) pela exposição excessiva a umidade o que não permitiu a coevolução dos ovinos e do parasito. Os ovinos se infectam após um período de seca, posterior a uma estação chuvosa. Assim, os animais ficam expostos à fase de vida livre do parasito (Bellato et al. 2009).

Através das características morfológicas das lesões hepáticas observadas neste estudo, a doença pode ser classificada em formas que variaram de subaguda à crônica. A forma subaguda caracterizou-se por áreas necróticas no parênquima hepático. Geralmente essa forma de apresentação ocorre 6-10 semanas após a ingestão das metacercárias e correspondem aos trajetos migratórios do parasito (Dow et al. 1968, Taylor et al. 2010). Microscopicamente, havia focos de acentuada necrose caseosa circundada por infiltrado granulomatoso e eosinofílico. Lesões semelhantes também são descritas na literatura para ovinos (Dow et al. 1968, Cullen \& Stalker 2016). Os casos em que houve predomínio de lesões fibróticas, principalmente nos ductos biliares, além da presença de parasitos adultos, sugeriram alterações mais crônicas da doença, que geralmente ocorre 4-5 meses após a ingestão de quantidades menores de metacercárias 
(Barros 2016). Praticamente não há mineralização de ductos biliares na doença em ovinos (Dow et al. 1968). Em bovinos, a forma crônica de fasciolose é comumente observada. Entretanto, diferentemente da espécie ovina, ocorre atrofia do parênquima hepático, principalmente, do lobo esquerdo, além de marcado espessamento e mineralização dos ductos biliares. Lesões necróticas, semelhantes às observadas na forma subaguda dos ovinos desse estudo, raramente estão presentes nos bovinos (Tessele et al. 2013).

Lesões decorrentes de Oesophagostomum spp. são frequentemente encontradas em frigoríficos de ovinos e bovinos (Tessele et al. 2013). Esses parasitos são denominados vermes nodulares e em ovinos as espécies Oesophagostomum columbianum e Oesophagostomum venulosum são as mais importantes e responsáveis pelas lesões. A infecção ocorre pela ingestão das larvas de terceiro estágio na vegetação (Taylor et al. 2010) e o local de predileção dos parasitos inclui o intestino grosso (Uzal et al. 2016). Semelhantemente ao que é descrito, observaram-se lesões nodulares na serosa e camada muscular do intestino delgado e grosso e nos linfonodos mesentéricos. Lesões no fígado, pulmão, mesentério e linfonodos mesentéricos estão relacionados à alta infecção parasitária (Uzal et al. 2016). No intestino, as larvas de terceiro estágio de Oesophagostomum spp. migram profundamente para dentro da mucosa, provocando nódulos de reação inflamatória. Posteriormente ocorre a muda para larva de quarto estágio. Na ocorrência da reinfecção, essa resposta é mais acentuada (Urquhart et al. 1996, Taylor et al. 2010). Histologicamente, a presença de cortes de larvas de Oesophagostomum spp. em meio as áreas de necrose caseosa nos intestinos e linfonodo mesentérico de alguns ovinos, confirmou a etiologia parasitária das lesões. Em suínos e bovinos, lesões semelhantes às observadas nesse estudo, também são descritas (Tessele et al. 2013, Uzal et al. 2016). Sugere-se que $O$. columbianum seja responsável pelas lesões visualizadas nos ovinos do presente trabalho, visto que $O$. venulosum raramente provoca formações nodulares (Taylor et al. 2010, Uzal et al. 2016).

\section{CONCLUSÕES}

Os resultados aqui apresentados demonstram que as principais alterações parasitárias observadas nas linhas de abate de ovinos incluem: hidatidose, cisticercose por Cysticercus ovis, sarcocistose (morfologia compatível com Stapelia gigantea), cisticercose por $C$. tenuicollis, fasciolose (Fasciola hepatica) e esofagostomose (Oesophagostomum spp.).

Morfologicamente os cistos hidáticos podem ser divididos em três padrões macroscópicos: cistos hidáticos uniloculares viáveis; cistos hidáticos multivesiculares viáveis; e cistos hidáticos (uniloculares e multivesiculares) degenerados. Hidátides multivesiculares viáveis constituíram uma apresentação frequente nos ovinos desse estudo.

Macroscopicamente, a capacidade infecciosa dos cistos de C. ovis pode ser avaliada quando essas estruturas são cortadas transversalmente. Músculo cardíaco e o músculo esquelético foram os principais locais anatômicos de predileção dos cistos.

Cistos de S. gigantea são facilmente identificados macroscopicamente, pois são estruturas brancas, grandes e salientes. Microscopicamente são delineados por uma fina cápsula basofílica que apresenta numerosos septos ramificados em direção ao lúmen que sustentam os bradizoítos.
Cistos de $C$. tenuicollis degenerados presentes no fígado são um importante diferencial de cistos hidáticos degenerados. Uma característica importante na diferenciação dessas condições está relacionada com a invasão do parênquima. Lesões de $C$. tenuicollis geralmente estão mais superficiais e aderidas na cápsula hepática com pouca invasão, enquanto que nos casos de hidatidose essa invasão é maior.

Lesões decorrentes de fasciolose subaguda constituíram um achado frequente nesse estudo e caracterizavam-se por alterações necróticas secundárias a migração do parasito.

Alterações provocadas por Oesophagostomum spp. foram observadas no intestino delgado, intestino grosso e linfonodos mesentéricos. As lesões eram nodulares, salientes, firmes e frequentemente mineralizadas.

A identificação morfológica correta das diferentes lesões parasitárias encontradas nas linhas de abate em frigoríficos de ovinos é extremamente importante para posterior destino correto das lesões e carcaças. Nos casos em que as lesões parasitárias estão degeneradas, estas devem ser cortadas transversalmente para avaliar o aspecto macroscópico da superfície de corte. Adicionalmente, devem-se conhecer os locais anatômicos mais comuns de ocorrência de cada alteração.

Agradecimentos.- Os autores agradecem aos médicos veterinários do Serviço de Inspeção Municipal (SIM) do município de Alegrete/RS, e ao proprietário e os funcionários do abatedouro Coxilha Vermelha pela disponibilidade e colaboração nesse estudo.

\section{REFERÊNCIAS}

Adrien M.L., Schild A.L., Marcolongo-Pereira C., Fiss L., Ruas J.L., Grecco F.B. \& Raffi M.B. 2013. Acute fasciolosis in cattle in southern Brazil. Pesq. Vet. Bras. 33(6):705-709. <http://dx.doi.org/10.1590/S0100-736X2013000600003>

Barros C.S.L. 2016. Fígado, vias biliares e pâncreas exócrino, p.237-244. In: Santos R.L. \& Alessi A.C. (Eds), Patologia Veterinária. $2^{\text {a }}$ ed. Roca, Rio de Janeiro. 842p.

Bellato V., Souza A.P. \& Veiga L.P.H.N. 2009. Trematodiose, p.95-109. In: Cavalcante A.C.R., Vieira L.S., Chagas A.C.S. \& Molento M.B. (Eds), Doenças Parasitárias de Caprinos e Ovinos: epidemiologia e controle. Embrapa Informação Tecnológica, Brasília. 603p.

Bowman D.D. 2014. Helminths, p.122-150. In: Ibid. (Ed.), Georgis' Parasitology for Veterinarians. 10th ed. Saunders Elsevier, Philadelphia. 477p.

Cardona G.A. \& Carmena D. 2013. A review of the global prevalence, molecular epidemiology and economics of cystic echinococcosis in production animals. Vet. Parasitol. 192(1/3):10-32. <http://dx.doi.org/10.1016/j. vetpar.2012.09.027><PMid:23084536>

Cooper B.J. \& Valentine B.A. 2016. Muscle and tendon, p.239-240. In: Maxie M.G. (Ed.), Jubb, Kennedy, and Palmer's Pathology of Domestic Animals. Vol.1. 6th ed. Elsevier, St Louis. 798p. <http://dx.doi.org/10.1016/B9780-7020-5317-7.00003-5>.

Cullen J.M. \& Stalker M.J. 2016. Liver and biliary system, p.318-324. In: Maxie M.G. (Ed.), Jubb, Kennedy, and Palmer's Pathology of Domestic Animals. Vol.2. 6th ed. Elsevier, St Louis. 654p. <http://dx.doi.org/10.1016/B9780-7020-5318-4.00008-5>.

Damboriarena P.A., Silveira C.S., Morais R.M. \& Anjos B.L. 2016. Natural Sarcocystis gigantea infection in sheep from Southern Brazil. Ciência Rural 469(7):1229-1233. <http://dx.doi.org/10.1590/0103-8478cr20151183>

Dehaghi M.M., Fallahi M., Sami M. \& Radfar M.H. 2013. Survey of sarcocystis infection in slaughtered sheep in Kerman Abattoir, Kerman, Iran. Comp. Clin. Pathol. 22(3):343-346. <http://dx.doi.org/10.1007/s00580-012-1414-9> 
Dow C., Ross J.G. \& Todd J.R. 1968. The histopathology of Fasciola hepatica infections in sheep. Parasitology 58(1):129-135. <http://dx.doi.org/10.1017/ S0031182000073480> <PMid:5689385>

Dubey J.P., Lindsay D.S., Speer C.A., Fayer R. \& Livingston Junior C.W.J. 1988. Sarcocystis arieticanis and other Sarcocystis species in sheep in the United States. J. Parasitol. 74(6):1033-1038. <http://dx.doi.org/10.2307/3282228> <PMid:3142990>

Eberhard M.L. 2014. Histopathologic diagnosis, p.412-416. In: Ibid. (Ed.), Georgis' Parasitology for Veterinarians. 10th ed. Saunders Elsevier, Philadelphia. 477p.

Erickson A. 2011. Taenia ovis (Sheep measles) infection in sheep. Department of Agriculture and Food, Government of Western Australia, South Perth. (Farmnote 471:1-2). Disponível em <http://www.wormboss.com.au/files/ pages/worms/tapeworms/sheep-measles/Farm_Note_471_Taenia_ovis_ sheep_measles_infection_in_sheep.pdf> Acesso em 7 abr. 2017.

Farhang-Pajuh F., Yakhchali M. \& Mardani K. 2014. Molecular determination of abundance of infection with Sarcocystis species in slaughtered sheep of Urmia, Iran. Vet. Res. Forum 5(3):181-186. <PMid:25568716>

Giudici C., Entrocasso C. \& Steffan P. 2013. Biología, fisiologia e inmunidad de los nematodos gastrointestinales y pulmonares, p.3-28. In: Fiel C. \& Nari A. (Eds), Enfermidades Parasitarias de Importancia Clínica y Productiva em Ruminantes. Editorial Hemisferio Sur, Montevideo. 752p.

Higino S.S.S., Pinheiro S.R., Rocha V.C.M., Souza G.O., Portela R.A., Alves C.J., Vasconcellos S.A., Dib C.C., Rosário T.R., Melville P.A. \& Azevedo S.S. 2013. Tuberculose em caprinos e ovinos abatidos no semiárido da Paraíba, Brasil. Arqs Inst. Biológico, São Paulo, 80(3):281-287.

IBGE 2013. Produção da Pecuária Municipal. Vol.41. Rio de Janeiro. (Comentários). Disponível em <ftp://ftp.ibge.gov.br/Producao_Pecuaria/ Producao_da_Pecuaria_Municipal/2013/comentarios.pdf> Acesso em 6 abr. 2017.

Kale M.C., Aral Y., Aydin E., Cevger Y., Sakarya E. \& Güloglu S.C. 2011. Determination of by-product economic values for slaughtered cattle and sheep. Kafkas Univ. Vet. Fak. 17(5):551.

Khanjari A., Cheraghi N., Bokaie S., Fallah S., Basti A.A., Fallah M. \& Mohammadkhan F. 2015. Prevalence of Cysticercus tenuicollis in slaughtered sheep and goats by season, sex, age, and infected organ at Amol abattoir, Mazandaran province. Iran. Comp. Clin. Pathol. 24(1):149-152. <http:// dx.doi.org/10.1007/s00580-013-1875-5>

Kul 0. \& Yildiz K. 2010. Multivesicular cysts in cattle: Characterisation of unusual hydatid cyst morphology caused by Echinococcus granulosus. Vet. Parasitol. 170(1/2):162-166. <http://dx.doi.org/10.1016/j.vetpar.2010.01.045> $<$ PMid:20207486>

Mitchell G. 2002. Update on fasciolosis in cattle and sheep: in practice. Vet. Rec. 24:378-385.

Morais D.F., Vilela V.L.R., Feitosa T.F., Santos V.M., Gouveia V.R., Athayde A.C.R. \& Azevêdo S.S. 2017. Prevalence and risk factors for Cysticercus tenuicollis in goats and sheep in Paraíba, northeastern Brazil. Braz. J. Vet. Parasitol. 26(2):235-238. <http://dx.doi.org/10.1590/s1984-29612016092> $<$ PMid:28146156>
Moro P. \& Schantz P.M. 2009. Echinococcosis: a review. Int. J. Infect. Dis. 13(2):125133. <http://dx.doi.org/10.1016/j.ijid.2008.03.037><PMid:18938096>

Oryan A., Moghaddar N. \& Gaur S.N.S. 1994. Metacestodes of sheep with special reference to their epidemiological status, pathogenesis and economic implications in fars province. Iran. Vet. Parasitol. 51(3-4):231-240. <http:// dx.doi.org/10.1016/0304-4017(94)90160-0><PMid:8171825>

Rey L. 2013. Echinococcus granulosus e hidatidose, p.540-557. In: Ibid. (Ed.), Parasitologia: parasitos e doenças parasitárias do homem nos trópicos ocidentais. $4^{\text {a }}$ ed. Guanabara Koogan, Rio de Janeiro.

Santos D.V., Santo M.C.B.E., Domingues E.H., Kohek Júnior I.K., Facin D.V. \& Vidor A.C. 2010. Análise das principais lesões encontradas nos abatedouros registrados na CISPOA. Informativo Técnico No 04/Ano 01. Disponível em <http://www2.agricultura.rs.gov.br/uploads/1284486430Informativo_ Tecnico_DPA_N._04.pdf> Acesso em 6 abr. 2017.

Scala A., Varcasia A. \& Garippa G. 2004. Cystic echinococcosis in Sardinia: the current role of sheep. Parassitologia 46(4):397-400. <PMid:16044699>

Singh B.B., Sharma R., Gill J.P.S. \& Sharma J.K. 2015. Prevalence and morphological characterization of Cysticercus tenuicollis (Taenia hydatigena cysts) in sheep and goat from north India. J. Parasit. Dis. 39(1):80-84. <http:// dx.doi.org/10.1007/s12639-013-0284-7><PMid:25698866>

Sissay M.M., Uggla A. \& Waller P.J. 2008. Prevalence and seasonal incidence of larval and adult cestode infections of sheep and goats in eastern Ethiopia. Trop. Anim. Health Prod. 40(6):387-394. <http://dx.doi.org/10.1007/ s11250-007-9096-z><PMid:18575964>

Soares L.B., Miquelotti D.R., Grisie L. \& Serra-Freire N.M. 2012. Indicadores de parasitismo por Cysticercus tenuicolis em pequenos ruminantes no Sertão Central do Estado do Ceará, Brasil. Revta Bras. Med. Vet. 34(2):106-110.

Souza D.A. 2012. Atualidade e perspectivas internacionais para a produção de carne ovina. Disponível em <http://www.milkpoint.com.br/radartecnico/ovinos-e-caprinos/atualidade-e-perspectivas-internacionaispara-a-producao-de-carne-ovina-78029n.aspx> Acesso em 6 abr. 2017.

Taylor M.A., Coop R.L. \& Wall R.L. 2010. Parasitologia Veterinária. $3^{\text {a }}$ ed. Guanabara Koogan, Rio de Janeiro. 742p.

Tessele B., Brum J.S. \& Barros C.S.L. 2013. Lesões parasitárias encontradas em bovinos abatidos para consumo humano. Pesq. Vet. Bras. 33(7):873-889. <http://dx.doi.org/10.1590/S0100-736X2013000700008>

Urquhart G.M., Armour J., Duncan J.L., Dunn A.M. \& Jennings F.W. 1996. Parasitologia Veterinária. $2^{a}$ ed. Guanabara Koogan, Rio de janeiro. 273p.

Uzal F.A., Plattner B.L. \& Hostetter J.M. 2016. Alimentary system, p.205-216. In: Maxie M.G. (Ed.), Jubb, Kennedy, and Palmer's Pathology of Domestic Animals. Vol.2. 6th ed. Elsevier, St Louis. 654p. <http://dx.doi.org/10.1016/ B978-0-7020-5318-4.00007-3>.

Viana J.G.A. 2008. Panorama geral da ovinocultura no mundo e no Brasil. Revta Ovinos 4(12):1-9. Disponível em <http://www.caprilvirtual.com. br/Artigos/panorama_geral_ovinocultura_mundo_brasil.pdf $>$ Acesso em 6 abr. 2017. 